\title{
Performance improvement of decentralized control for bidirectional converters in a DC micro-grid
}

\author{
Seyed Mojtaba Abbasi, Mehdi Nafar, Mohsen Simab \\ Department of Electrical Engineering, Marvdasht Branch, Islamic Azad University, Marvdasht, Iran
}

\begin{tabular}{l} 
Article Info \\
\hline Article history: \\
Received Mar 30, 2021 \\
Revised Jul 3, 2021 \\
Accepted Jul 14, 2021 \\
\hline
\end{tabular}

Keywords:

DC micro-grid

Circulating current

Converter

Power allocation

Voltage control

\begin{abstract}
In this paper, using a neural controller and a genetic optimization algorithm to control the voltage as well as, control the frequency of the grid along with the management of the reactive power of the micro-grid to control the output power during islanding using Simultaneous bilateral power converters with voltage/frequency droop strategy and optimization of PI coefficients of parallel power converters by genetic-neural micro-grid algorithm to suppress AC side-current flow that increases stability and improvement of conditions frequency and voltage are discussed. Given the performance of the microgrid in two simulation scenarios, namely transition from on-grid to off-grid, the occurrence of a step change in load in island mode as well as return to working mode is connected. The ability to detect the robust performance and proper performance of two-level neural controller. The controller performance time was also very good, indicating the appropriate features of the method used to design the controller, namely two-level neural, genetics. The main advantage of this method is its simplicity of design. The method used is also efficient and resistant to changes in the system, which results from the simulations.
\end{abstract}

This is an open access article under the CC BY-SA license.

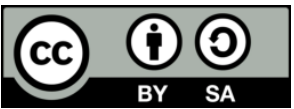

\section{Corresponding Author:}

Mehdi Nafar

Department of Electrical Engineering

Marvdasht Branch

Islamic Azad University, Marvdasht, Iran

Email: mnafar@miau.ac.ir

\section{INTRODUCTION}

In recent years, much attention has been paid to micro-grid $s$ in distributed networks and the presence of this technology has changed the nature of distribution networks. Kai et al. [1] deals with voltage control from the point of view of the distribution micro-grid operator with the aim of minimizing losses. The general system under study by Xia et al. [2] is as follows: Several microgrids are connected to the main network by converters. Dynamic Planning Algorithm is used to calculate island voltage profiles of micro-grid connectivity to electric vehicles in order to improve voltage control and maximize power by particle swarm algorithm [3]. On the basis of the traditional fuzzy PI controller, the double fuzzy PI controller is realized by adding the sub fuzzy controller, which generates the auxiliary correction of PI parameters due to the AC side voltage variation and DC side given voltage variation of the reversible three-phase PWM converter [4]. Consideration of DG for short-term island micro-grid studies seems more feasible [5]. In addition to the control of the voltage and frequency control of the islanded microgrid, it is also important to carefully analyze the dynamic analysis of the microgrid system that dominates the low frequency modes of the system largely affected by the performance of the inverter's power sharing mechanism [6]. This unit controls the performance and protection of micro-grids with regard to the state of dispersed production resources [7]. 
Wang et al. [9] analyzes the flow path in a parallel two-way power converter system and controls a control strategy of total and divergent control. For asymmetric power grid conditions, a control strategy is proposed to increase the ability to transmit active power without oscillating circulation current. This strategy mainly focuses on the positive and negative components of the sequence, but does not consider the zero sequence components that can exist among parallel converters. An improved secondary distribution control method based on low bandwidth communication system for DC voltage recovery and assurance of DC current distribution accuracy is presented in [10]. The proposed control method consists mainly of three compensator controllers proportional to the integral used to change the voltage and adjust the slope of the curve. The tuning parameters (KP, Ki) of PI controller for a three-phase voltage regulator is designed using PSO algorithm in [11]. The PSO algorithm and ITSE as fitness function is integrated to find the optimal tuning based on the nonlinearity behaviour of each component in the system without depending on the analytical method for linearizing the system which cannot ensure the best control performance.

The voltage and frequency of the microgrid are determined. When the microgrid is disconnected from the mains and operates in island mode, the control strategy must be changed to provide a reference for frequency and voltage [12]. A droop control scheme is generally used by paralleling multiple inverters [13] in which the voltage and frequency of each inverter are adjusted in order to control the active and reactive power. By way of the industrial development, control objects keep getting more complicated, particularly for the unknown parameters or slow variations in large delay, time-changing, non-linear complicated systems, with random interference or delay. However, The Proportional Integral Derivative (PID) control has simple structure and linear behavior. Moreover, it gives acceptable performance for several industrial applications [14]. Ambrish explained that the conventional tuning methods have very limited capability which further diminishes in case the explicit mathematical model is not available [15]. Ander et al. [16] highlights the role of power electronics in microgrids, especially inverter voltage sources, and introduces a precise method as a precise and proven approach to controlling microgrids. GA-PID controllers were simulated with MATLAB, and the GA optimisation method used to optimise the membership function and gains of the associated PID controller in [17]. The performance of the GA-PID in a DC-DC buck converter was investigated by simulating and analysing maximum overshoot, peak time, and steady state time based on ISE, IAE, IATE and MSE Criteria.

In this research, the microgrid presented in [18] has been used with some changes in production resources and times in order to evaluate the proposed method for frequency control. The single-line diagram of the test system, showing that each low-voltage microgrid is connected to the mains by a static switch; It includes loads, controllable and uncontrollable sources as well as storage devices (flywheels with batteries). An improved secondary distribution control method based on an LBC system is presented for DC voltage recovery and assurance of the accuracy of DC current distribution. The proposed control method is mainly composed of three proportional-integral (PI) controllers that are used to change the voltage and adjust the slope drop of the curve [19]. All of these control strategies for the DC grid are mainly focused on the islanded mode, neglecting the grid-connected mode. A new idea that can be added to this type of $\mathrm{P}_{\mathrm{DC}}-\mathrm{V}_{\mathrm{DC}}{ }^{2}$ droop control [20] is system frequency adaptation, which demands redesign of the $\mathrm{P}_{\mathrm{DC}}-\mathrm{V}_{\mathrm{DC}}{ }^{2}$ droop control. In [21] The overall structure of the microgrid examined in this microgrid includes a photovoltaic system, fuel cell and battery as energy storage. These distributed generation sources are connected to a 700-volt bus via a DC-to-DC converter. The direction of power in the photovoltaic system and the battery is one-way, but the DC-to-DC converter of the battery will have a two-way converter due to its function of energy storage. Rosero et al. [22] specifies the allocation of active power and frequency regulation in the drop-down control method for independent microgrids under electrical and communication error. In the AC microgrid, frequency control is performed intelligently by the pso algorithm using fuzzy adjustment [23]. Several microgrids are connected to the main network by converters in [24]. The output of these converters, which are connected by lines with Z-impedance, was of DC type, but the microgrids themselves are of AC type and are controlled by Drop control. Basic system information such as DC link voltage and microgrid frequency is sent to the Droop controller. This structure consists of a bipolar bridge thyristor, DC link capacitor, L selfie filter. Tungadio shows that excess energy produced by the photovoltaic system is stored in the battery, and when the production of the photovoltaic system decreases, the battery will be responsible for providing electrical energy [25]. If the SOC of the battery is less than a certain value, the fuel cell also enters the network and the task.

\section{MODELING AND FORMULATION}

The overall structure of the micro-grid investigated in the paper is illustrated in Figure 1. It contains a photovoltaic system, a fuel cell and a battery as a power generation and energy storage system. These distributed generation sources are connected to the 700-volt bus via the DC-to-DC converter. The 
directionality of the photovoltaic system is one-way, but the DC-to-DC battery converter have a bidirectional converter due to its energy saving function. The extra energy generated by the photovoltaic system is stored in the battery, and when the photovoltaic system output is reduced, the battery will have the power to supply electricity. If the battery SOC is lower than the specified amount, the fuel cell connected to grid and will have the task of recharging the battery and supplying part of the load. The DC to AC converter connects the voltage produced in the DC bus to the AC grid or loads.

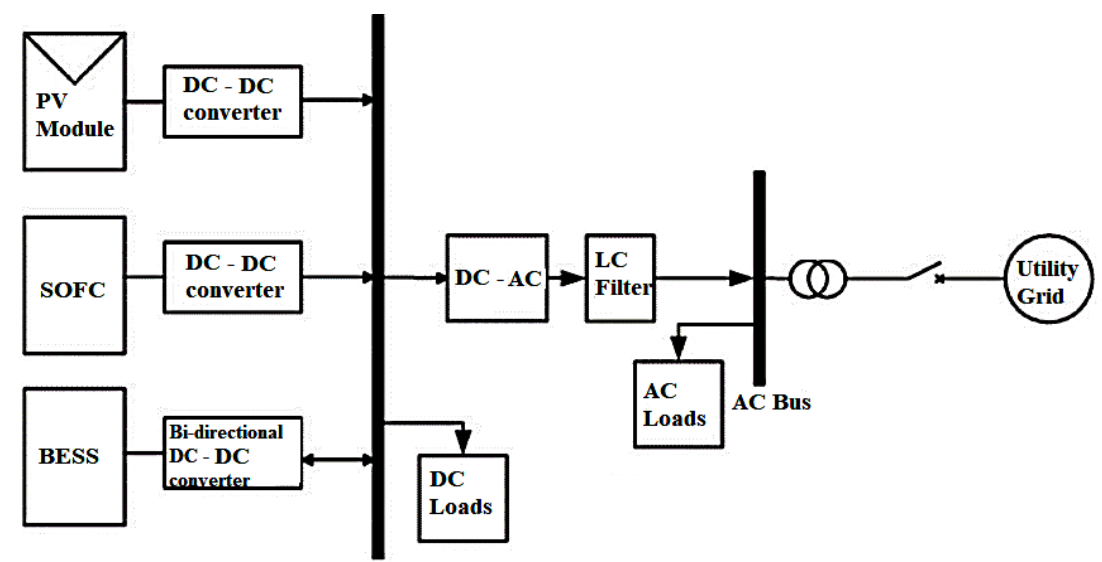

Figure 1. The micro-grid studied

\section{CONTROL METHOD}

In the following, the control method is described to suppress the circulation current by appropriately determining the transverse poles of the control conversion at a stable point. It should be noted that when connected to the grid, maintaining the proper voltage and frequency profiles and its stability is provided by the main grid. Accordingly, the inverters in the micro-grid are controlled in such a way that the active and reactive power are injected into the micro-grid by DGs. The outline of the proposed control is presented in the following Figure 2.

Base on Figure 2, The current and voltage of the three-phase grid are then converted to dq components and compared with the reference values obtained from the reference and reactive power. The difference between them is minimized by a PI controller; the controller output, after switching to three-phase mode and passing through a pulse wave generator, provides the control signals needed to control the inverter. So, the inverter with the pulses provided during a specific process forces the existing DGs to follow their output power, the $\mathrm{P}_{\text {ref }}$ and $\mathrm{Q}_{\text {ref }}$ values.

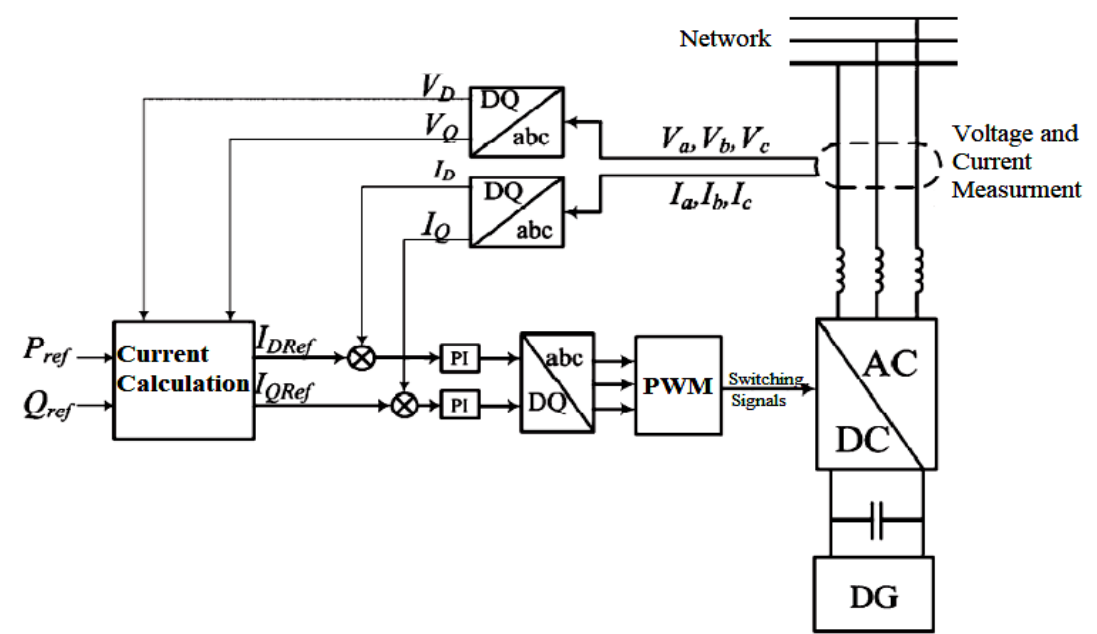

Figure 2. The control framework of the proposed method 
In disconnection mode, since reference values for the voltage range and frequency are not provided through the grid, it is therefore necessary to control the DGs to reconstruct these values, which is to act as a synchronous generator on the grid. The basis of frequency and voltage control in conventional power systems is often provided by several control loops, which will be briefly introduced in the following. The first control loop is based on the drop-off characteristic of the synchronous generators; this is called primary control. This control loop is mounted on synchronous generators. The basis of the operation of this control loop is shown in Figure 3 (a) and Figure 3 (b).

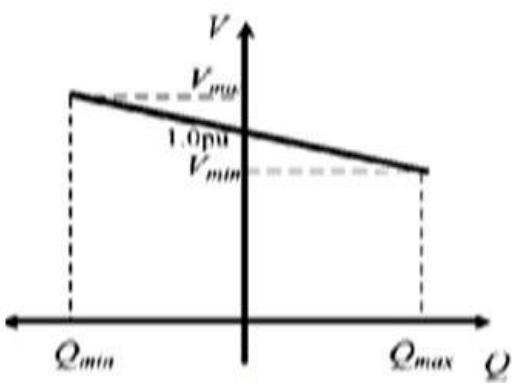

(a)

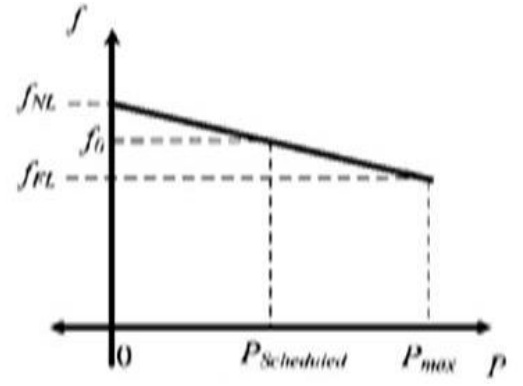

(b)

Figure 3. Initial control by droop characteristic for (a), voltage and (b) frequency adjustment

According to the Figures 3 (a), 3 (b), if the real and imaginary power depart from the nominal values, the frequency and voltage also shift with the power changes. The primary control loop limits the frequency and voltage Droop caused by the load change to a certain value and prevents its continuous loss and instability. This is illustrated in the Figure 4 and Figure 5. But the disadvantage of this control loop is that it is unable to return voltage and frequency to nominal values. And it is necessary to use a complementary or secondary control loop. A secondary control loop is used in order to zero the error in the voltage or frequency profile as shown in the Figure 4. The value of persistent frequency error is often set to zero by a classical PI controller.

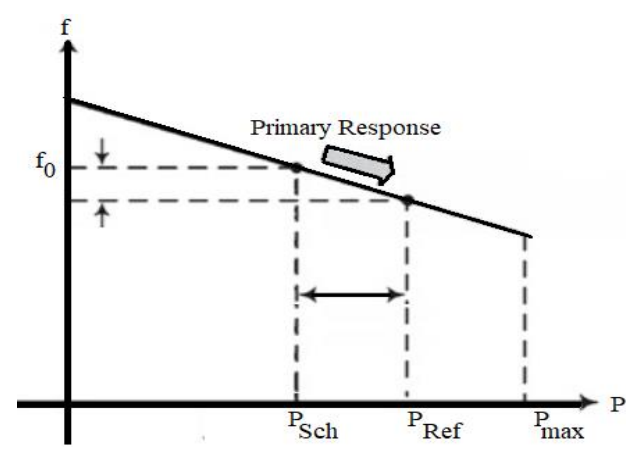

Figure 4. Frequency droop restricted by primary control

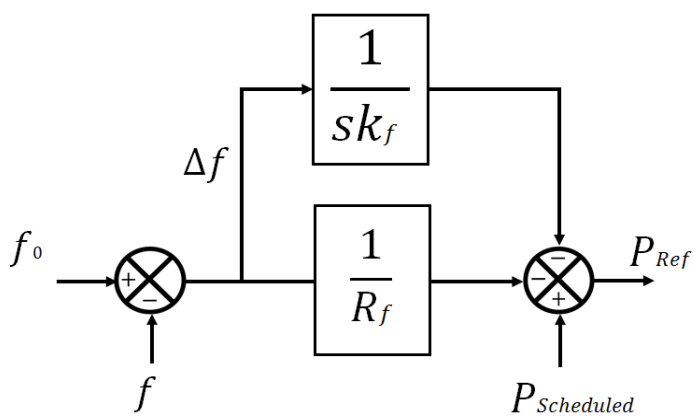

Figure 5. Secondary control framework

When disconnected from the main grid, they enable the micro-grid to implement primary and secondary control methods by applying the VSI control method, which is still based on the active presence of electronic power elements. The general structure of this method is shown in Figure 6. According to this method, one or more DGs are responsible for stabilizing the micro-grid frequency and voltage or, in other words, applying one or more DGs to the VSI method and controlling the other DGs for supplying local micro-grid loads. 


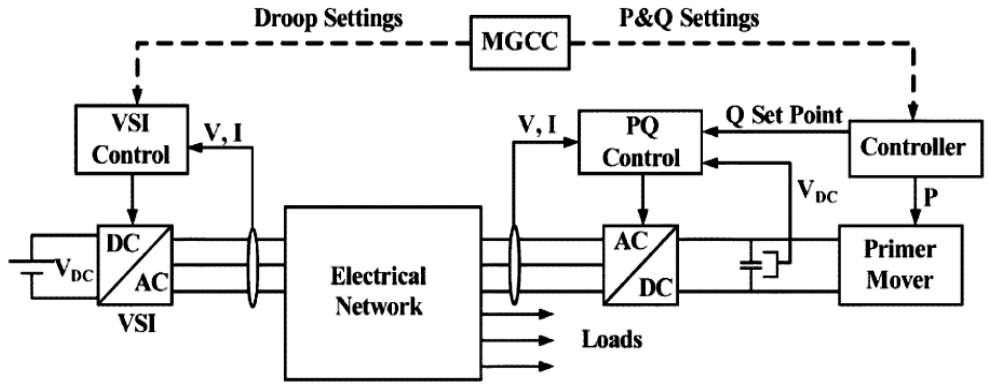

Figure 6. Control framework

\section{ARTIFICIAL NEURAL NETWORK}

Based on the structure of these networks and how to integrate the processing elements, there are several important and important applications such as mind modeling, financial modeling, time series prediction, control systems and optimization for it. To apply artificial neural networks to the processes mentioned above, we need to consider a mathematical model of them. A simple mathematical model to analyze its behavior is shown Figure 7 . Based on Figure 7 , The $X, W$, and $\theta, f_{\text {(net) }}$ vectors are the input vectors and weights, the bias value, and the function intended for the neuron, respectively. The output of this model will be in accordance with the equation given in (1).

$$
y(k)=f\left(\sum_{j=1}^{n} w_{j} x_{j}(K)+W_{0} \theta\right) .
$$

The advantage of nonlinear functions over linear functions is in updating weights and training, and makes the system not subject to sudden changes.

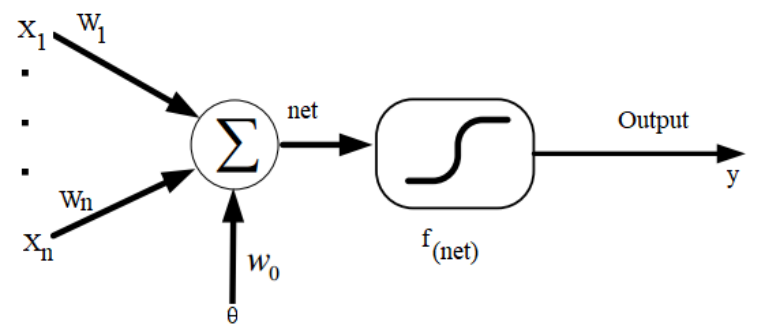

Figure 7. Mathematical modeling of a type of artificial neural networks.

\section{ELEMENTAL MODELING}

\subsection{Modeling the photovoltaic system}

The electrical model of a photovoltaic cell is shown in Figure 8. The model includes a reverse diode and a parallel current source. And both series and parallel resistors simulate system losses.

$$
\begin{aligned}
& I_{p v}=N_{p} I_{p h}-N_{p} I_{s}\left[\exp \left(\frac{q\left(\frac{V_{p v}}{N_{S}}+I_{p v} \frac{R_{s}}{N_{p}}\right)}{K T_{c} A}\right)-1\right] \\
& I_{p h}=\frac{\left[I_{s c}+k_{1}\left(T_{c}-T_{r e f}\right)\right] \lambda}{1000} \\
& I_{s}=I_{r s}\left(\frac{T_{c}}{T_{r e f}}\right)^{3} \exp \left(\frac{q E_{g}\left(\frac{1}{T_{r e f}}-\frac{1}{T_{c}}\right)}{K A}\right)
\end{aligned}
$$

Where $I_{s}$ the cell saturation current, $N_{p}$ and $N_{s}$ number of series and parallel arrays, $V_{p v}$ output voltage of solar system, q electron charge, k Boltzaman constant, $\mathrm{I}_{\mathrm{rs}}$ and $\mathrm{I}_{\mathrm{sc}}$ reverse saturation current and 
short circuit, Eg silicon fission energy, $\mathrm{k} 1$ coefficient The temperature dependence and $\lambda$ are the amount of radiation. The solar system under consideration is $50 \mathrm{~kW}$ and consists of 33 parallel modules and 5 series modules. All solar system parameters are taken from [5].

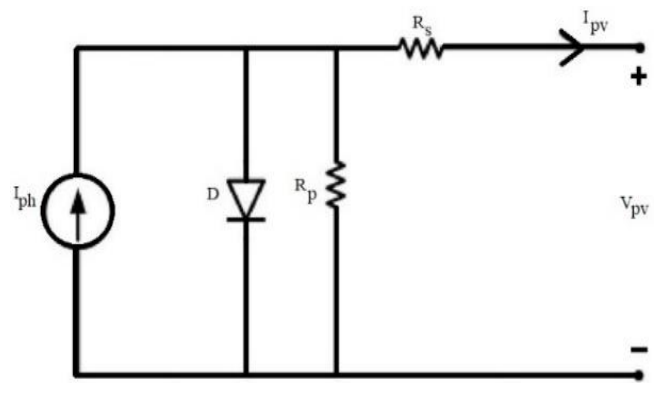

Figure 8. Model of a photovoltaic cell

\subsection{Energy storage system}

The battery model in this study is a controllable voltage source with a series resistor as presented in [5]. The following equations are presented in this study for battery modeling.

$$
\begin{aligned}
& E=E_{0}-K \frac{Q_{b}}{Q_{b}-\int i_{b} d t}+A * \exp \left(B \int i_{b} d t\right) \\
& E_{\text {batt }}=E-R_{b} I_{b} \\
& S O C=100\left(1+\frac{\int i_{b} d t}{Q_{b}}\right)
\end{aligned}
$$

Where E0 is the open circuit voltage, Qb the battery capacity, $\mathrm{K}$ the polarizing voltage, $\mathrm{B}$ is the exponential capacity, and $\mathrm{A}$ is the exponential voltage.

\subsection{Fuel cell}

Fuel cells are a new technology for the production of electricity that produces electricity directly from the combination of fuel and oxidizer. The constant voltage produced by the fuel cell can be obtained by:

$$
\begin{aligned}
& V_{f c}=N_{0}\left(E_{0}+\frac{R T}{2 F} \ln \left(\frac{p \mathrm{H}_{2} \mathrm{PO}_{2}^{0.5}}{p \mathrm{H}_{2} \mathrm{PO}}\right)\right)-r I_{f c} \\
& q H_{2}^{i n}=\frac{1}{1+s T_{f}}\left[\frac{2 k r}{\text { Uopt }} I_{f c}\right] \\
& q O_{2}^{i n}=\frac{1}{r H O} q H_{2}^{i n} \\
& p H_{2} \mathrm{O}=\frac{\frac{1}{\mathrm{KH}_{2} \mathrm{O}}}{1+s_{\tau} \mathrm{H}_{2} \mathrm{O}}\left[\frac{1}{r H O} q H_{2}^{i n}-k r I_{f c}\right] \\
& p \mathrm{H}_{2} \mathrm{O}=\frac{\frac{1}{\mathrm{KH}_{2} \mathrm{O}}}{1+s_{\tau} \mathrm{H}_{2} \mathrm{O}}\left[2 k r I_{f c}\right]
\end{aligned}
$$

where E0 is the standard cell voltage, N0 is the cell number, $r$ is the gas constant, $\mathrm{f}$ is the Faraday constant, $\mathrm{r}$ is the stack resistance, $\mathrm{T}$ is the cell temperature $\mathrm{pH}_{2}, \mathrm{pO}_{2}$ and $\mathrm{pH} 2 \mathrm{O}$ hydrogen pressure, oxygen and water vapor. The dynamic model of SOFC is presented by the following relationships in the paper.

\section{CONTROL ON COMPONENT}

\subsection{Photovoltaic system control}

The DC-to-DC converter will be responsible for controlling the photovoltaic system. This converter is responsible for increasing the voltage produced by the PV and obtaining maximum power from the PV. 
The method, shortly known as the disturbance method, is a common and widely used method in maximum power tracking algorithms. This method is essentially a trial-and-error method and does not require temperature and radiation sensors and cell characteristic curves. The photovoltaic controller slightly changes the base value of the inverter output and observes the actual output power value. If the output power is increased, this change will continue. The flowchart of this method is shown in Figure 9.

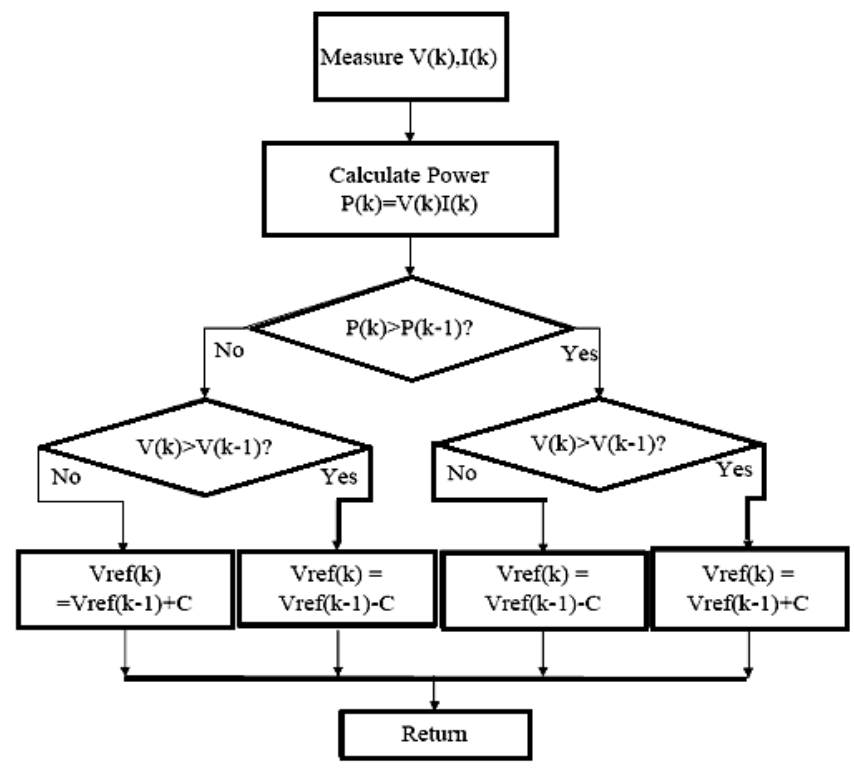

Figure 9. P\&O flowchart

\subsection{Battery (energy storage) control}

The battery is connected to the 700-volt bus via a DC-to-DC converter. The primary task of the battery is to save the extra power generated by the photovoltaic system until the power output from the PV is low or a large load is fed into the micro-grid to supply the micro-grid. In addition, the battery is responsible for maintaining the DC link voltage constant. The SOFC control block diagram in Figure 10 also describes the steps. If the power generation by the PV is low or the load is increased so that the PV alone cannot supply it, the battery will have the main task of power supply. If the battery charge is less than $20 \%$, discharging the battery further reduces the life of the battery. In this case, the fuel cell can enter the grid and supply the charge as well as charge the battery.

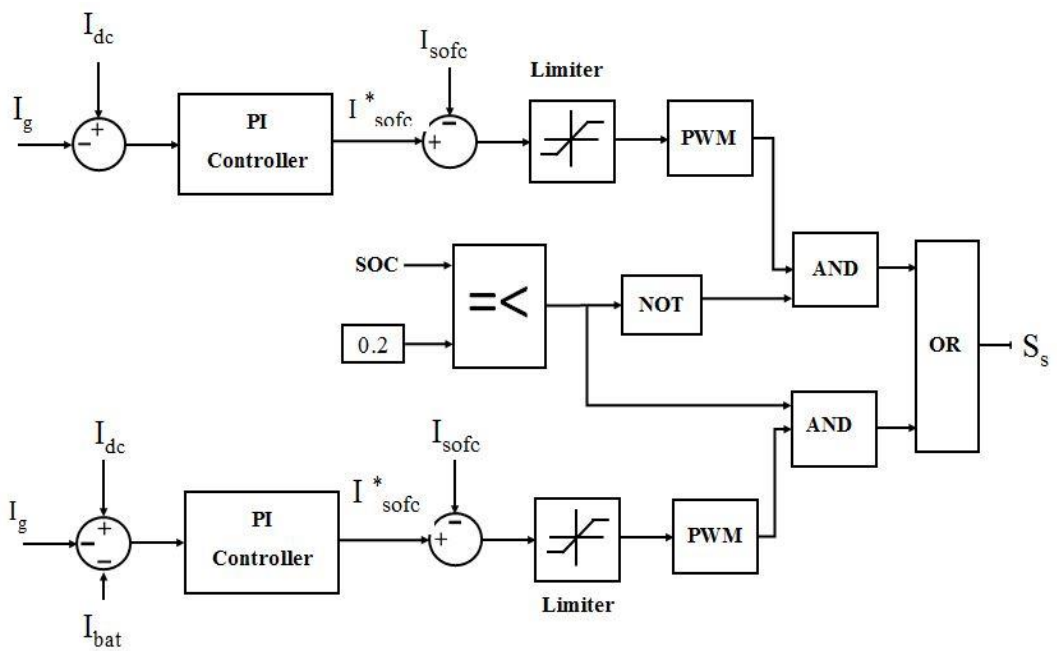

Figure 10. SOFC control block diagram 


\subsection{DC-to-DC converter control}

Boost converter pulses are produced according to the proposed $\mathrm{P} \& \mathrm{O}$ method. Boost converter pulses are injected using the block diagram method above. An example of a photovoltaic system is listed in the block diagram. The following Figure 11 shows the DC-to-DC converter.

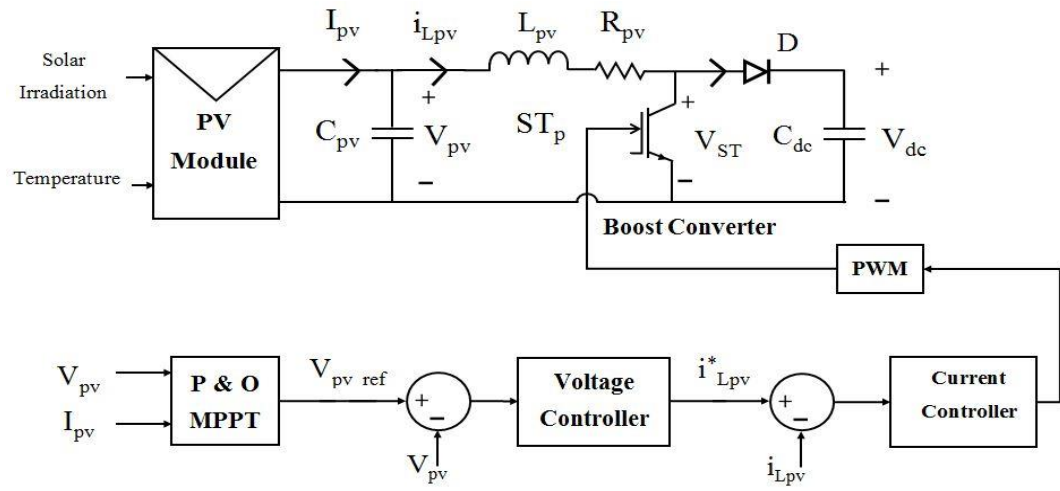

Figure 11. DC-to-DC converter control block diagram

\subsection{Principles of $\mathrm{L}$ and $\mathrm{C}$ design appropriate to prevent circulation}

The converter design for the purpose of having a stable pole involves correctly selecting the values of the inductors and capacitors. The design presented below is based on constant input voltage and output voltage which also confirms the variable input voltage and constant output voltage, so the following: Transformer design indicators are covered: selective $\mathrm{L}_{1}$ depends on the maximum number of current ripples $i_{1}$, in the steady state, the peak-to-peak $i_{1}$ Current changes during the time the switch is closed follows:

$$
\Delta i_{1}=\frac{K}{L_{1} f_{s}}\left(V_{i}-V_{o}\right) .
$$

The voltage at terminal $L_{1}$ is the same during both the on and off switches and the $f_{s}$ switching frequency depends on the intended use, so in each operating condition the $\mathrm{L}_{1}$ inductance value is determined based on the maximum value. When the switch is on, the capacitor $\mathrm{C}_{0}$ starts charging to replace it when the switch is off, and the capacitor $\mathrm{C}_{0}$ must select the voltage ripples that can be calculated from the following formula:

$$
\Delta v_{o}=\frac{\Delta q_{o}}{C_{o}}=\frac{\Delta i_{o}}{8 \times C_{o} \times f_{s}} .
$$

Which delta $i_{0}$ can be calculated from Equation delta $i_{1}+$ delta $i_{2}$ and delta $i_{2}$ from the following formula:

$$
\Delta i_{2}=\frac{K}{L_{2} f_{s}}\left(V_{c n}-V_{o}\right) .
$$

By putting in equation delta $\mathrm{i}_{0}$ we have:

$$
\Delta v_{o}=\left(\Delta i_{1}+\Delta i_{2}\right)\left[\frac{1}{8 \times C_{o} f_{s}}\right] \text {. }
$$

\subsection{Select the values of $C_{n}$ and $L_{2}$}

The purpose is to obtain a polynomial response with the least number of oscillations, elevations, and also the lowest sitting time. In order to avoid the inherent effects of minimum phase, a weighted cost function is defined as:

$$
E=\sum_{n=1}^{n=m}\left(V_{o}^{*}-w v_{o}\left[n T_{n}\right]\right)^{2}
$$


While $\mathrm{V}^{*}{ }_{0}$ the output voltage value is ideal, $\mathrm{V}_{0}\left[\mathrm{nT}_{\mathrm{n}}\right], \mathrm{n}$ the faithful sample of voltage response due to duty cycle variations is also the number of all samples. The values for the weighting factor are carefully adjusted, $\mathrm{w}=1$, as for $\mathrm{V}_{0}\left[\mathrm{nT}_{\mathrm{n}}\right]>\mathrm{V}_{0}[0]$ and $\mathrm{w}=0.985$ for the rest of the states. These values are selected in such a way that the difference expressed by the minimum phase is minimized (due to the transient voltage response) $\mathrm{Cn}$ and $\mathrm{L}_{2}$ the values will be obtained if the minimum value is established. To have a choice $\mathrm{L}_{2}$ it is necessary to consider $C_{0}$ a reset from the equation above. Since $L_{1}$ and $L_{2}$ both values will have an effect on the values delta $i_{1}$ and delta $i_{2}$ therefore $C_{0}$ the value is updated and can be re-used again, this process continues until it reaches the lowest possible values $\Delta v_{o}$ and $\mathrm{E}$ the defined range.

\subsection{Circuit flow control}

Linear resistance between bidirectional power converters for parallel bidirectional power converters is the input and output that shows the colored sections of the circulating paths between the bidirectional power converters, as shown below. When the switching status of two-way power converters is different, there is a voltage Droop between the two-way power converters, then a circulating current is generated along the path if the system Droop is low. The high switch path is on and the low switch path in phase (a) of the first two way power converter is off, while the high switch path is off and the low switch path in phase (a) of the second two way power converter is on. Then a circular flow path is formed that is indicated by the arrow and can be derived in an equivalent circuit. Based on the above analysis, an additional zero axis is introduced which mainly comprises asymmetric components. Circulation flow analysis, circulating flow paths and the equivalent circuit of a pair of BPC are shown in Figure 12.
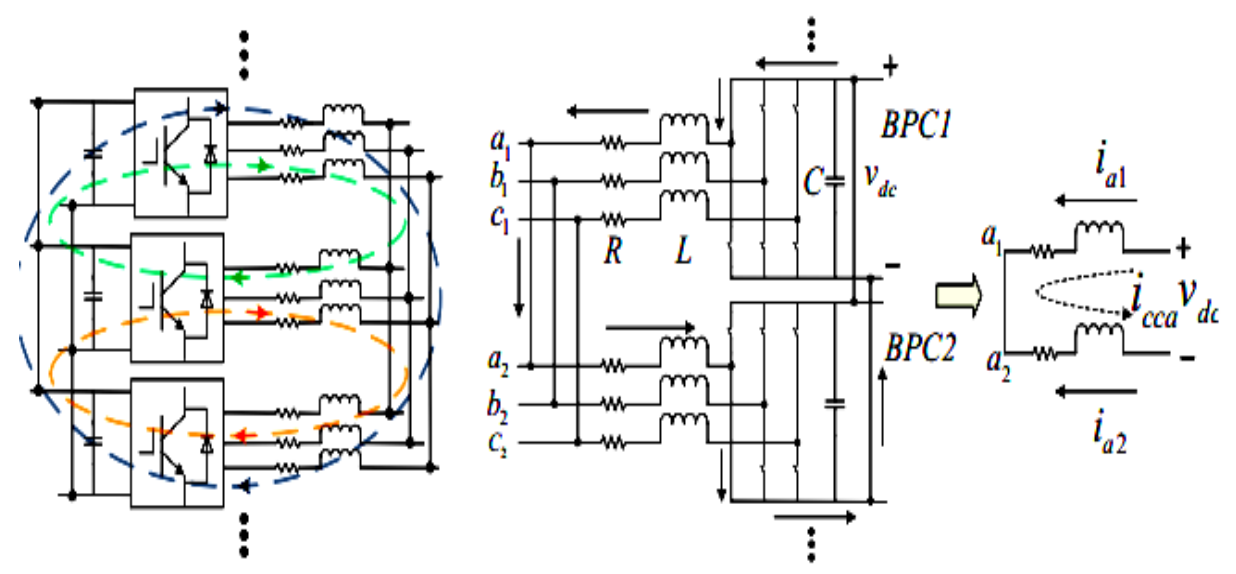

Figure 12. The circulation flow is formed between the phases and its equivalent circuit

The new power system requires increased intelligence and flexibility in control and optimization to ensure load balancing and production capabilities in the event of disturbances. These common changes and uncertainties in a power grid equipped with a classic controller are not able to control the grid in the right direction. Therefore, in this paper, using the online intelligent neural system and its integration with the genetic algorithm is used to optimize and tune the PI controller coefficients. There are several methods to obtain the best PI controller performance and to determine the controller-related coefficients in practice, we've used the neuro to optimize. Neural Genetic Algorithm is a method of optimization that operates on the principle of survival most appropriate in living things.

\section{RESULTS AND DISCUSSION}

The micro-grid under studying includes a photovoltaic system with a capacity of $50 \mathrm{~kW}$, a fuel cell with a capacity of $100 \mathrm{~kW}$ and a battery with the capacity of Ah 250. The amount of sunlight and battery SOC varied in these two case studies and the performance of the control system for voltage control was evaluated. The general structure of the studied micro-grid is shown in Figure 13. 


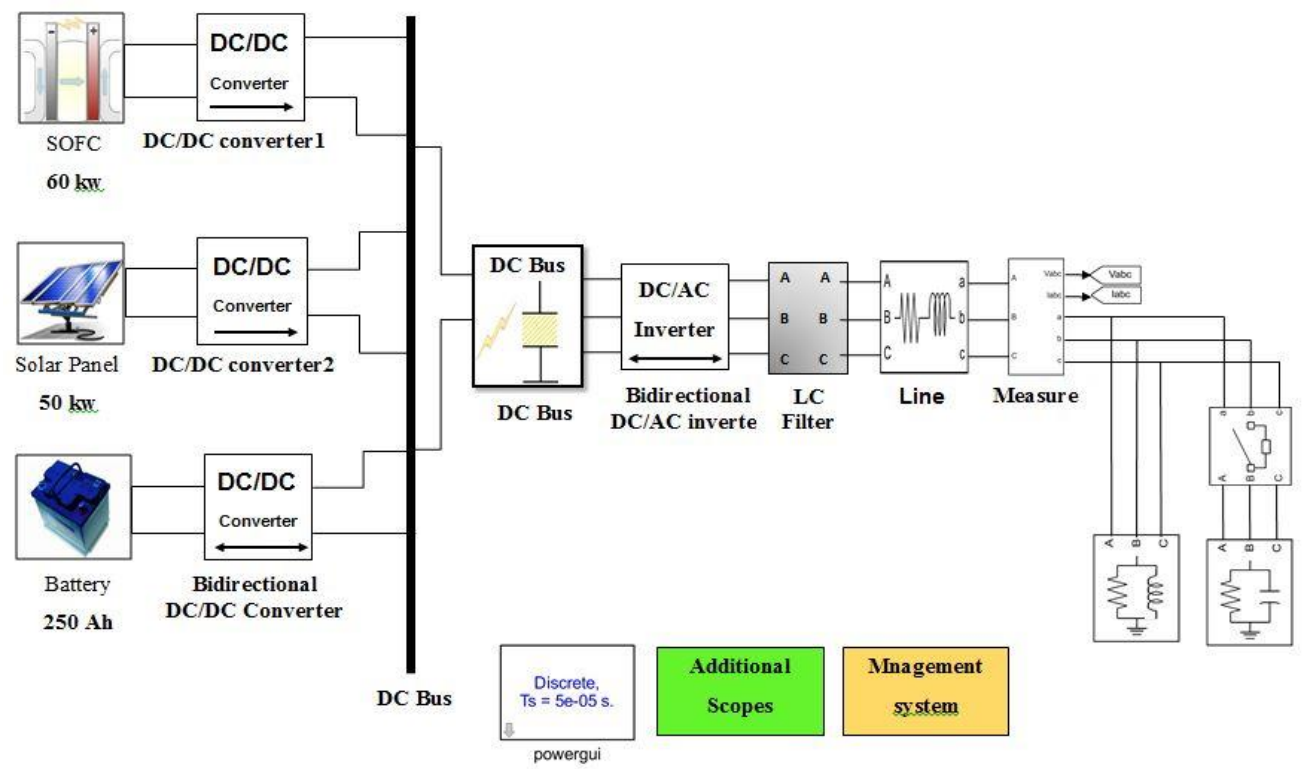

Figure 13. Overall structure of the studied micro-grid

To evaluate the efficiency of the designed genetic neural model, the two datasets are selected from real and training data as test data and compared. They are also plotted in the form of two datasets. Comparison of real and micro-grid data shows that the training process has been performed with great accuracy and that the neural has well reconstructed the system behavior. It is important to remember that 80 $\%$ of the data are used for training, $10 \%$ for testing and the other $10 \%$ for validation. Based on the information given, Figure 14 indicates the degree of conformity of the data with the predicted values.
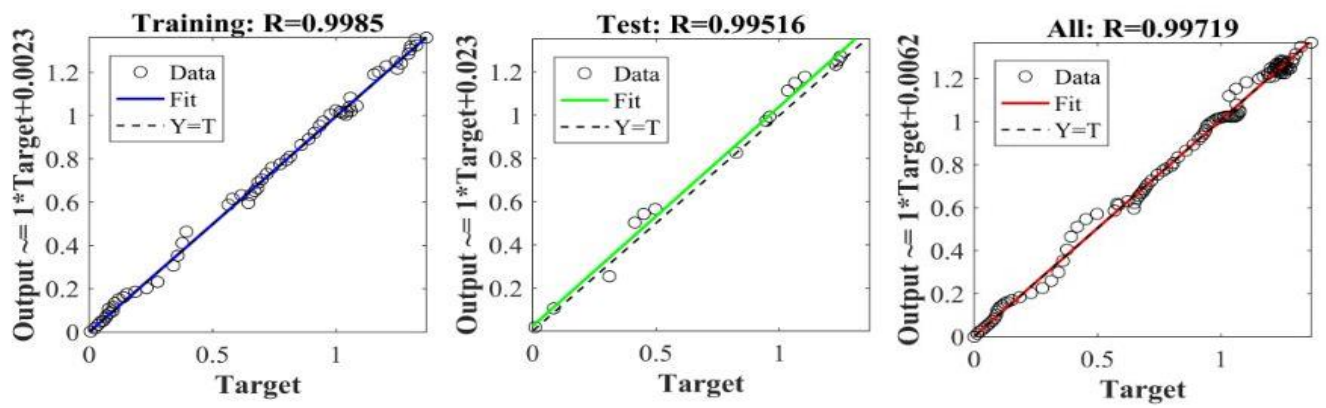

Figure 14. Regression curve

Figure 15, curve shows the extent to which the data are consistent with the predicted values. As can be seen, it is very well adapted. The Figure 15 shows the performance of the neural network for data during the training, verification and testing process, which reached its acceptable responses after approximately 400 rounds and the slope decreased. 


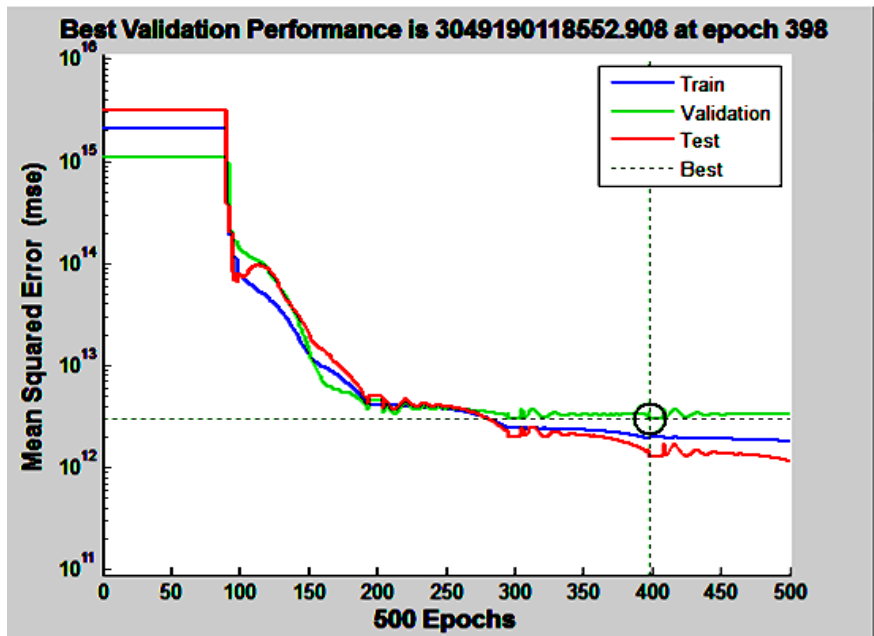

Figure 15. Micro-grid performance

In this case scenario, the initial battery charge is assumed to be $18 \%$. At first the sun's radiation is $400 \mathrm{w} / \mathrm{m}^{2}$ and it reaches zero at $\mathrm{t}=0.4 \mathrm{sec}$. Initially, the resistor-selfie resistor is connected to the system with a $40 \mathrm{~kW}$ active power and a $10 \mathrm{kvar}$ reactive power. At the moment $\mathrm{t}=0.6 \mathrm{sec}$ the active power is increased by $10 \mathrm{~kW}$. The input and output scenarios are clearly shown in Figure 16 to Figure 22.

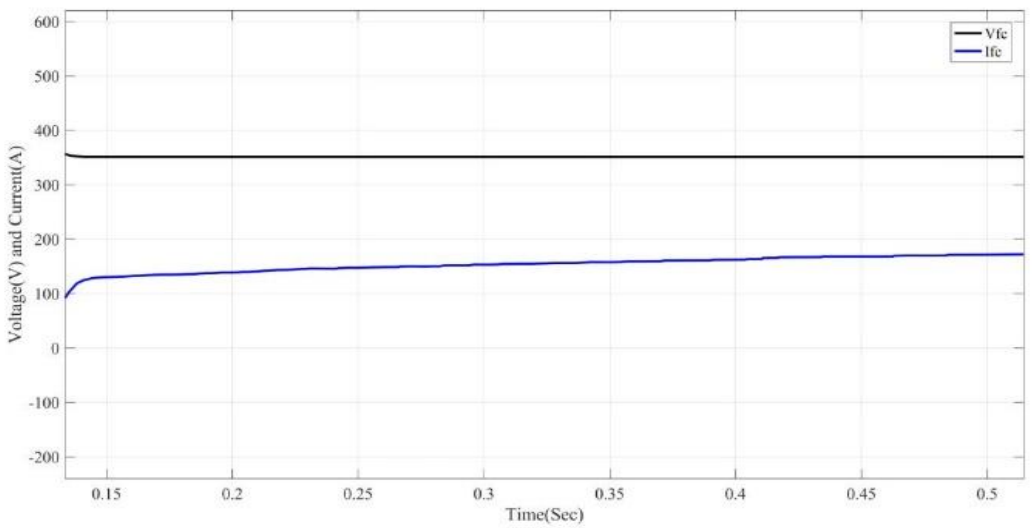

Figure 16. The solar system radiates and temperature
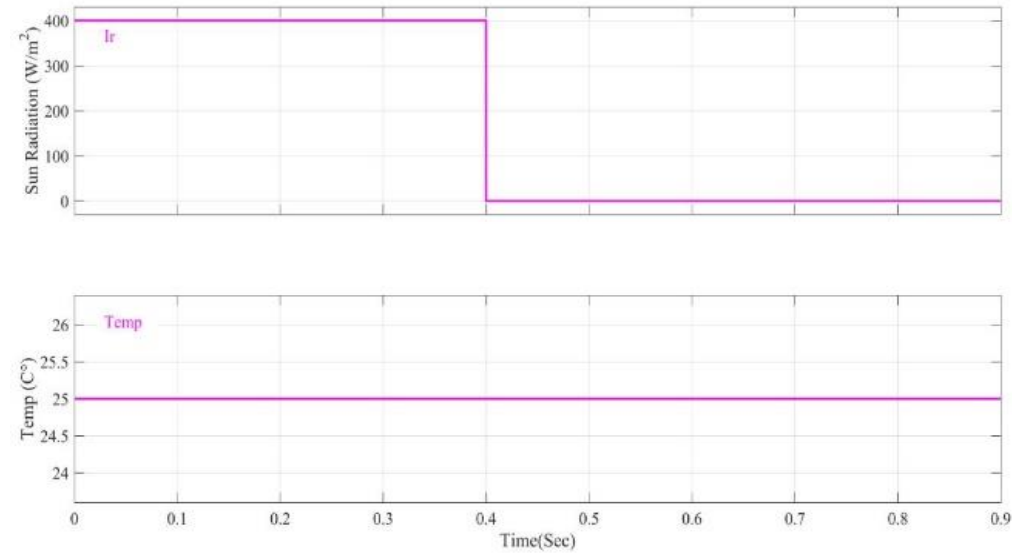

Figure 17. Voltage and current fuel cell obtained from the simulations

Performance improvement of decentralized control for bidirectional converters ... (Seyed Mojtaba Abbasi) 


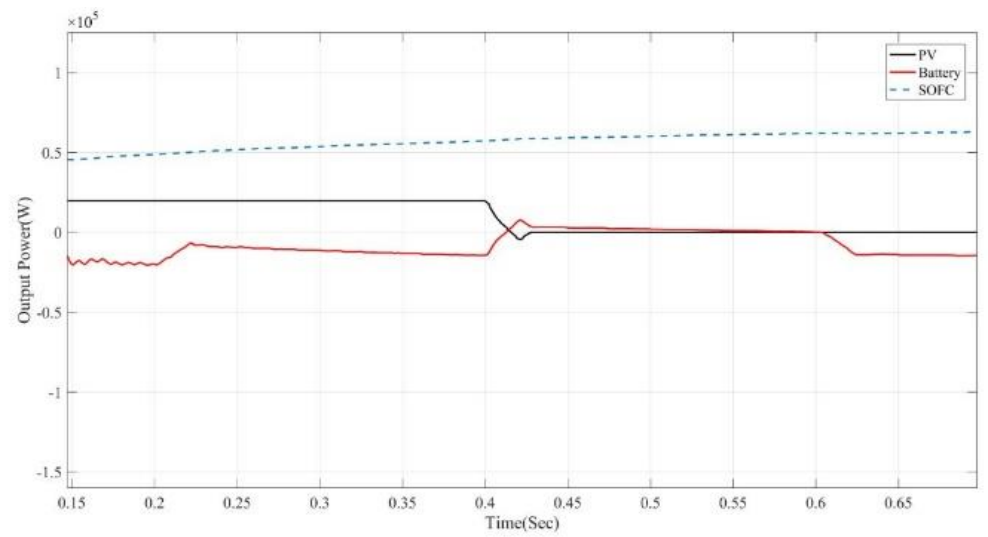

Figure 18. Battery voltage and current

As shown in Figure 19, until the moment $\mathrm{t}=0.4$ seconds, the battery is receiving power from the network to be charged, and after this moment, because the power of the photovoltaic system moves to zero, the battery enters the network and with the help of SOFC system, Supply the entire system load. At $\mathrm{t}=0.6$ seconds, due to the new active load entering the network and the need to charge the batteries, the SOFC system alone compensates for this power shortage. In Figure 21, at $\mathrm{t}=0.6$ seconds, we see the demand for new active power in the network, which causes a drop in the frequency of the network side, which the control systems used well, and in a very short time, bring the system frequency to $50 \mathrm{~Hz}$.

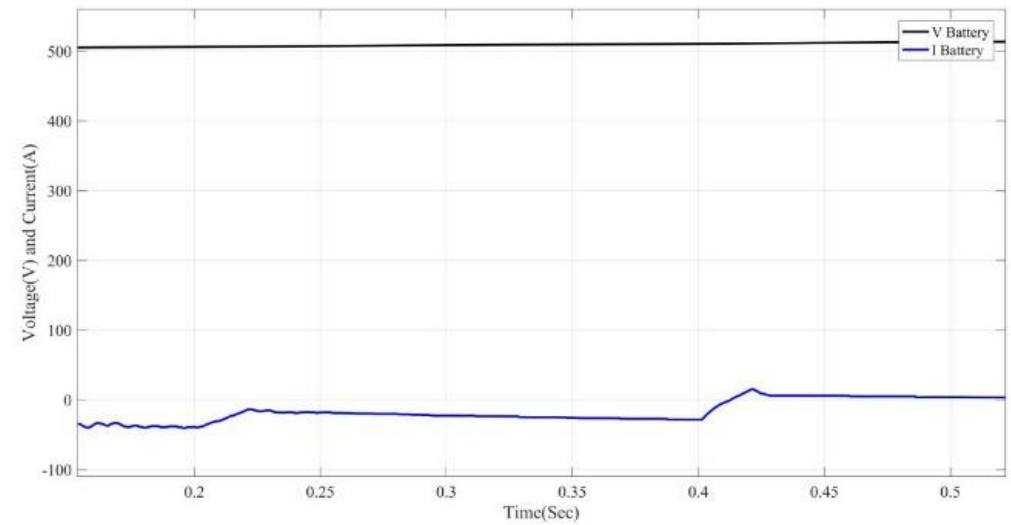

Figure 19. The output power of the elements

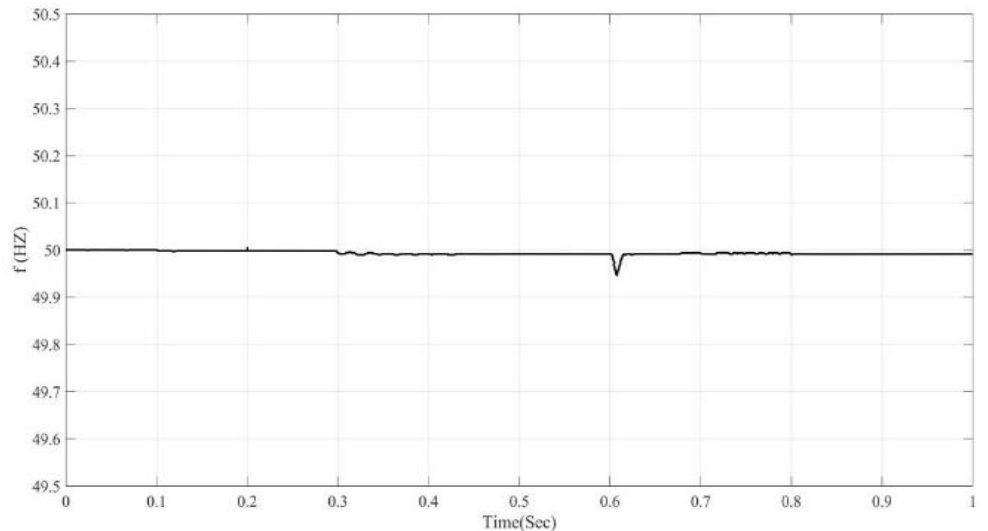

Figure 20. DC link voltage 


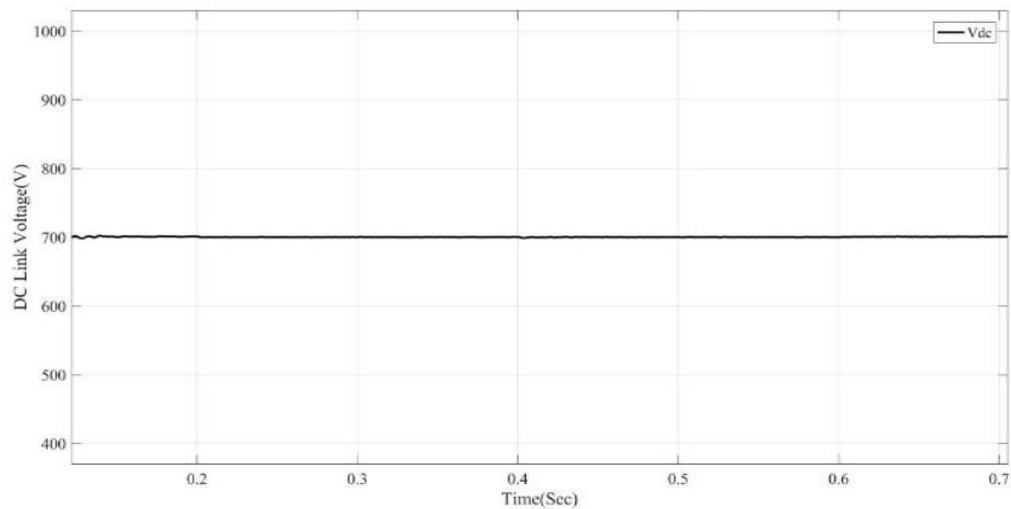

Figure 21. System frequency studied
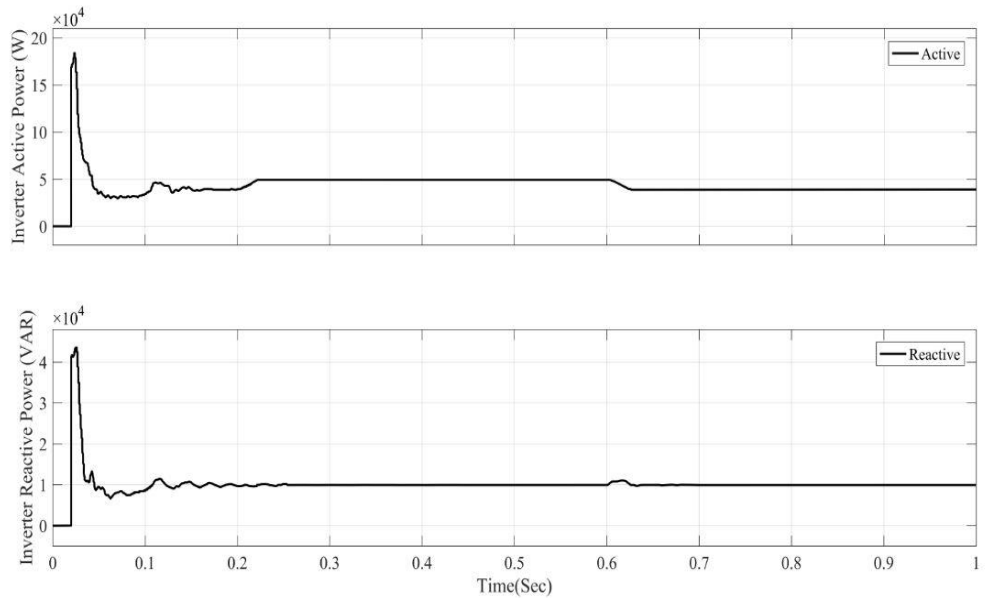

Figure 22. Inverter output power study scenario obtained from the simulations.

According to Figure 22, by connecting the network to the inverter, at the beginning and up to $t=0.2$ seconds, the active and reactive powers of the network increase due to the circulating currents caused by switching in the active and reactive state, which causes the control system Circulating currents are suppressed and controlled. At $\mathrm{t}=0.4$ seconds, when there is no sunlight and the output power through the photovoltaic system is zero, the DC link voltage is fixed via the battery and SOFC, and the inverter output remains constant. At $\mathrm{t}=0.6$ seconds, according to the scenario, we have an increase in active load, which causes the frequency of the system to decrease, which, based on the designed control system, quickly returns to normal. Due to the reduction of system voltage, the reactive power of the inverter increases to keep the voltage constant (control mode). Because the power of the inverter remains constant, increasing the reactive power reduces the active power of the inverter.

In Figures 23 to 25, various components such as inverter output power, DC voltage link and converter AC currents in different modes, including the use of conventional methods in determining PI control coefficients and the use of genetic algorithms and the use of neural-genetic algorithms compared with each other. As can be clearly seen in the output diagrams, using the method used in this paper, i.e., using the genetic-neural algorithm, is more appropriate and efficient. 


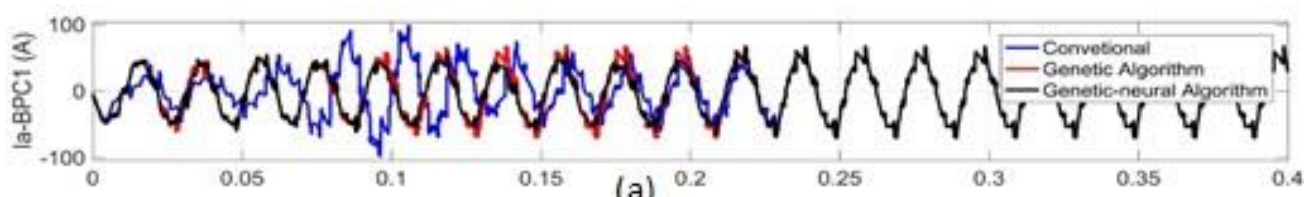

(a)
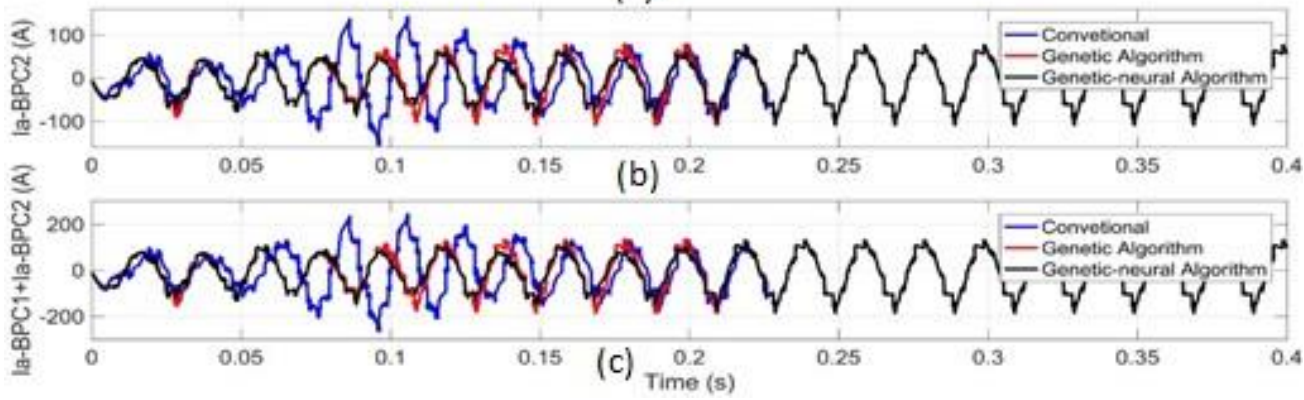

Figure 23. Comparison of AC currents in power converter, (a) changes in circulating current;(b) changes in electric current; (c) sum of the changes in circulating electric current.

Figure 23 shows the changes in electric current of two power converters and their sum using the conventional state control, using the genetic algorithm and using the control of the genetic-neural algorithm. Figure 23 (a) shows the changes in circulating current bpc1 and Figure 23 (b) shows the changes in electric current bpc2. Also shown in Figure 23 (c) is the sum of the changes in circulating electric current at two bpc. The AC current of two bidirectional power converters fluctuates due to the large number of asymmetric components present, but the sum of these currents is normal. This means that if only $\mathrm{d}-\mathrm{q}$ axis control is used, there is a circulating current between the BPCs (conventional mode). From the results, it can be seen that the $\mathrm{AC}$ current of the two BPCs in the case of using the genetic algorithm and using the genetic-neural algorithm is both smooth and normal and the asymmetric components are further reduced. Therefore, the circulating current can be reduced with further proposed control and the effects of suppressing the circulating current created between the power converters are clearly known. To suppress circulating current, the Rcc virtual resistor is designed on the 0 axis, which mainly consists of asymmetric components. From a control point of view, the virtual resistance RCC is similar to the active drop control, so it can reduce the circulating current. Reducing this current will improve the reduction of power losses and also prevent damage to the converter switches and ultimately increase the system reliability and stability and continuity of the system in power transmission.

As shown in Figure 24, with a conventional controller, the DC voltage has a greater amplitude of oscillation. The amplitude of oscillations and duration of oscillations in the proposed method of this paper, ie the use of genetic-neural algorithm, has a lower value and has been able to reduce the sitting time of the curve and follow the DC link voltage more appropriately and better and retrieve faster and more accurately.

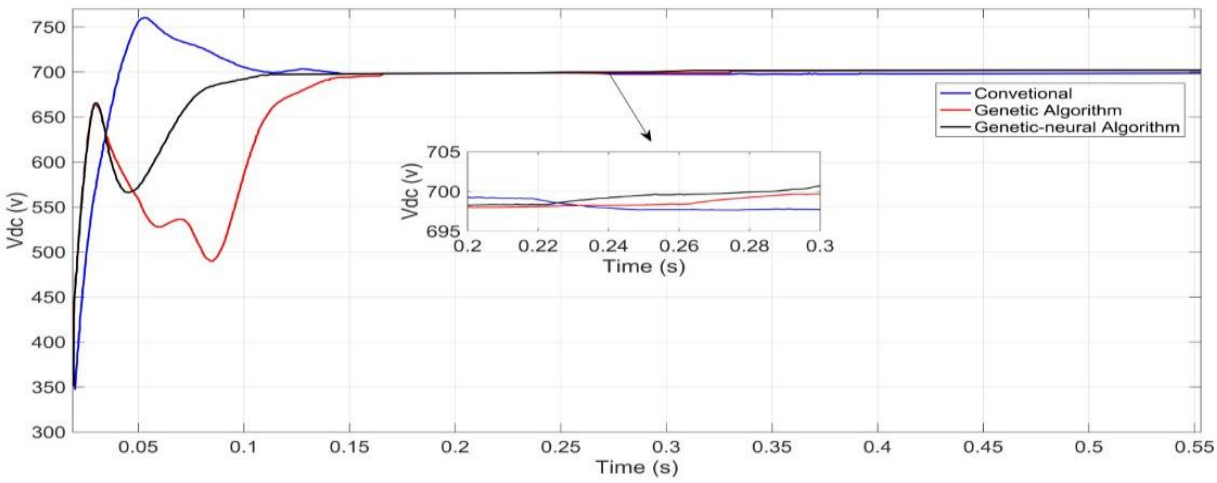

Figure 24. Comparison of voltage link at switching moment 
As shown in Figure 25, the power of the AC network side has more fluctuations using conventional mode control, while by optimizing the PI coefficients through the genetic algorithm, the amplitude of the oscillation decreases and by optimizing the controller coefficients through the genetic-neural algorithm has more recovery oscillations and the power consumption of the switching mode in the microgrid is much less than the conventional mode. In addition, optimizing PI coefficients using evolutionary algorithms has improved the accuracy and speed of coefficient determination.

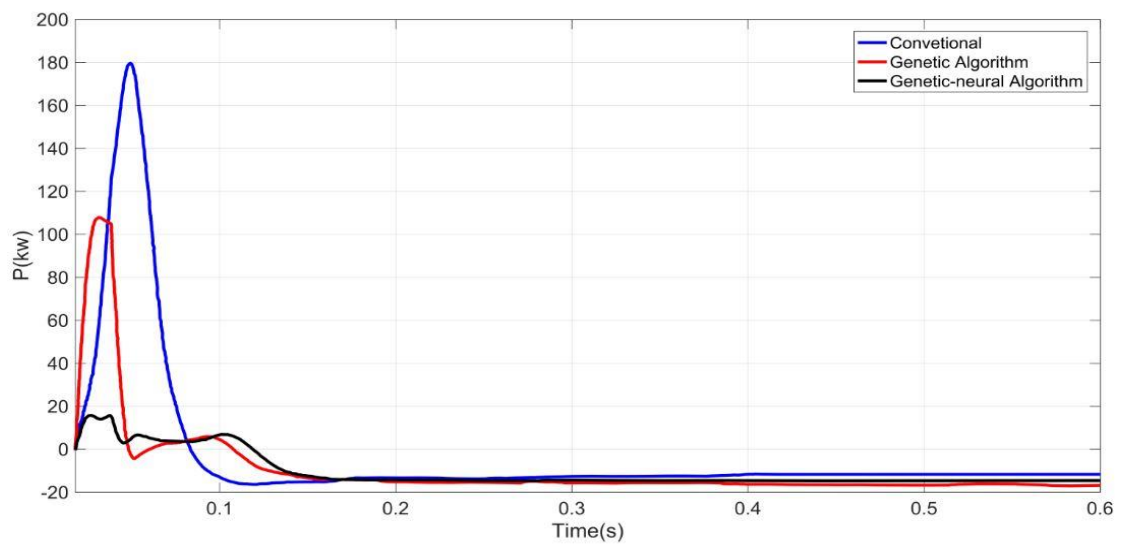

Figure 25. Compare the inverter output power at the moment of connection to the upstream

\section{CONCLUSION}

In this paper, using a neural controller and a genetic optimization algorithm to control the voltage as well as to the side, to control the frequency of the grid along with the management of the reactive power of the micro-grid to control the output power during isolation using simultaneous bilateral power converters with voltage/frequency droop strategy and optimization of PI coefficients of parallel power converters by genetic-neural micro-grid algorithm to suppress AC side-current flow to improve stability and improve conditions frequency and voltage are paid. Given the performance of the micro-grid in two simulation scenarios, namely transition from disconnected to off-grid, the occurrence of a step change in load in island mode as well as return to working mode is connected. Capability to deliver robust performance and proper performance of the neural controller. The controller performance time was also very good, indicating the appropriate features of the method used to design the controller, namely two-level neural, genetics. The main advantage of this method is its simplicity of design. The method used is also efficient and resistant to changes in the system, which results from the simulations.

\section{REFERENCE}

[1] K. Wang, X. Yuan, Y. Geng, and X. Wu, "A practical structure and control for reactive power sharing in microgrid," in IEEE Transactions on Smart Grid, vol. 10, no. 2, pp. 1880-1888, March 2019, doi: 10.1109/TSG.2017.2779846.

[2] X. Chen, M. Shi, H. Sun, Y. Li, and H. He, "Distributed cooperative control and stability analysis of multiple DC Electric Springs in a DC Microgrid," in IEEE Transactions on Industrial Electronics, vol. 65, no. 7, pp. 5611-5622, July 2018, doi: 10.1109/TIE.2017.2779414.

[3] M. A. Masrur, A. G. Skowronska, J. Hancock, S. W. Kolhoff, D. Z. McGrew, J. C. Vandiver, and J. Gatherer, "Military-based vehicle-to-grid and vehicle-to-vehicle microgrid-system architecture and implementation," in IEEE Transactions on Transportation Electrification, vol. 4, no. 1, pp. 157-171, March 2018, doi: 10.1109/TTE.2017.2779268.

[4] W. Zhang, Y. Fang, R. Ye, and Z. Wang, "Analysis and design of a double fuzzy PI controller of a voltage outer loop in a reversible three-phase PWM converter." Energies, vol. 13, 3778, 2020, doi: 10.3390/en13153778.

[5] Y. Xia, W. Wei, Y. Peng, P. Yang, and M. Yu, "Decentralized coordination control for parallel bidirectional power converters in a grid-connected DC microgrid," in IEEE Transactions on Smart Grid, vol. 9, no. 6, pp. 6850-6861, Nov. 2018, doi: 10.1109/TSG.2017.2725987.

[6] Y. Xia, M. Yu, P. Yang, Y. Peng, and W. Wei, "Generation-storage coordination for islanded DC microgrids dominated by PV generators," in IEEE Transactions on Energy Conversion, vol. 34, no. 1, pp. 130-138, March 2019, doi: 10.1109/TEC.2018.2860247.

[7] Y. Wang, C. Wang, L. Xu, J. Meng, and Y. Hei, "Adjustable inertial response from the converter with adaptive droop control in DC grids," in IEEE Transactions on Smart Grid, vol. 10, no. 3, pp. 3198-3209, May 2019, doi: 
10.1109/TSG.2018.2820160.

[8] F. Wang, Y. Wang, Q. Gao, C. Wang, and Y. Liu, "A control strategy for suppressing circulating currents in parallel-connected PMSM drives with individual DC links," in IEEE Transactions on Power Electronics, vol. 31, no. 2, pp. 1680-1691, Feb. 2016, doi: 10.1109/TPEL.2015.2422791.

[9] Y. Xia, Y. Peng, H. Hu, Y. Wang, and W. Wei, "Advanced unified decentralized control method with voltage restoration for DC microgrids," IET Renew. Power Gener, vol. 10, no. 6, pp. 861-871, 2016, doi:10.1049/ietrpg.2015.0433.

[10] H. Xiao, A. Luo, Z. Shuai, G. Jin, and Y. Huang, "an improved control method for multiple bidirectional power converters in hybrid AC/DC microgrid," in IEEE Transactions on Smart Grid, vol. 7, no. 1, pp. 340-347, Jan. 2016, doi: 10.1109/TSG.2015.2469758.

[11] M. Ismail, Y. Mohamed, A. El-Sawy, and A. A. Elbaset, "Optimal tuning of pi controller parameters for threephase AC-DC-AC converter based on particle swarm algorithm," International Middle-East Power System Conference (MEPCON'15) At: Mansoura University, Egypt, 2015, vol. 17.

[12] N. Hosseinzadeh, A. Al Shereiqi, M. Albadi, and A. Al-Hinai, "Constructing a multi-microgrid with the inclusion of renewable energy in Oman's rural power system," The Journal of Engineering Research [TJER], vol. 15, no. pp. 61-72, 2018, doi: 10.24200/tjer.vol15iss1pp61-72.

[13] A. W. N. Husna, M. A. Roslan, and M. H. Mat, "Droop control technique for equal power sharing in islanded microgrid," International Journal of Power Electronics and Drive Systems (IJPEDS), vol. 10, no. 1, pp. 530-537, 2019, doi: 10.11591/ijpeds.v10.i1.pp530-537.

[14] Mohamed. A. Shamseldin, Mohamed Sallam, A. M. Bassiuny, A. M. Abdel Ghany, "A novel self-tuning fractional order PID control based on optimal model reference adaptive system," International Journal of Power Electronics and Drive System (IJPEDS), vol. 10, no. 1, 2019, doi: 10.11591/ijpeds.v10.i1.pp230-241.

[15] D. C. Meena, and A. Devanshu, "Genetic algorithm tuned PID controller for process control," 2017 International Conference on Inventive Systems and Control (ICISC), 2017, pp. 1-6, doi: 10.1109/ICISC.2017.8068639.

[16] A. Ordono, E. Unamuno, J. A. Barren,a and J. Paniagua, "Interlinking converters and their contribution to primary regulation: a review," International Journal of Electrical Power \& Energy Systems, vol. 111, pp. 44-57, October 2019, doi: 10.1016/j.ijepes.2019.03.057.

[17] A. Chlaihawi, "Genetic algorithm error criteria as applied to PID controller DC-DC buck converter parameters: an investigation," IOP Conference Series: Materials Science and Engineering, vol. 671, 2020, 012032, doi: 10.1088/1757-899X/671/1/012032.

[18] M. Abuhilaleh, L. Li, M. Begum, and J. Zhu, "Power management and control strategy for hybrid AC/DC microgrids in autonomous operation mode," 2017 20th International Conference on Electrical Machines and Systems (ICEMS), 2017, pp. 1-6, doi: 10.1109/ICEMS.2017.8056435.

[19] P. Wang, X. Lu, X. Yang, W. Wang, and D. Xu, "An improved distributed secondary control method for DC microgrids with enhanced dynamic current sharing performance," in IEEE Transactions on Power Electronics, vol. 31, no. 9, pp. 6658-6673, Sept. 2016, doi: 10.1109/TPEL.2015.2499310.

[20] Y. Xia, W. Wei, Y. Peng, P. Yang, and M. Yu, "decentralized coordination control for parallel bidirectional power converters in a grid-connected DC microgrid," in IEEE Transactions on Smart Grid, vol. 9, no. 6, pp. 6850-6861, Nov. 2018, doi: 10.1109/TSG.2017.2725987.

[21] Y. Khayat et al., "Decentralized optimal frequency control in autonomous microgrids," in IEEE Transactions on Power Systems, vol. 34, no. 3, pp. 2345-2353, May 2019, doi: 10.1109/TPWRS.2018.2889671.

[22] C. X. Rosero, M. Velasco, P. Martí, A. Camacho, J. Miret, and M. Castilla, "Active power sharing and frequency regulation in droop-free control for islanded microgrids under electrical and communication failures," in IEEE Transactions on Industrial Electronics, vol. 67, no. 8, pp. 6461-6472, Aug. 2020, doi: 10.1109/TIE.2019.2939959.

[23] T. Nguyen, H. Yoo, and H. Kim, "A droop frequency control for maintaining different frequency qualities in a stand-alone multimicrogrid system," in IEEE Transactions on Sustainable Energy, vol. 9, no. 2, pp. 599-609, April 2018, doi: 10.1109/TSTE.2017.2749438.

[24] Z. Zhang, C. Dou, D. Yue, B. Zhang, and W. Luo. "A decentralized control method for frequency restoration and accurate reactive power sharing in islanded microgrids," Journal of the Franklin Institute, vol. 355, no. 17, pp. 8874-8890, 2018, doi: 10.1016/j.jfranklin.2018.09.024.

[25] D. H. Tungadio, and Y. Sun. "Load frequency controllers considering renewable energy integration in power system,” Energy Reports, vol. 5, pp. 436-453, 2019, doi: 10.1016/j.egyr.2019.04.003. 